\title{
Integration of the predictions of two models with dose measurements in a case study of children exposed to the emissions of a lead smelter
}

\author{
${ }^{1}$ R. Bonnard and ${ }^{2}$ T.E. McKone \\ ${ }^{1}$ INERIS (Institut National de l'Environnement Industriel et des Risques) \\ Parc Technologique Alata, 60550 \\ Verneuil-en-Halatte, France \\ ${ }^{2}$ Environmental Energy Technologies Division \\ Lawrence Berkeley National Laboratory \\ Berkeley, CA 94720
}

March 2009

This work was supported in part by the US Environmental Protection Agency through Interagency Agreement DW-988-38190-01-0 carried out through the US Department of Energy contract Grant No. DE-AC02-05CH11231. McKone was also supported by Cooperative Agreement Number U19/EH000097-03 from the US Centers for Disease Control and Prevention (CDC). 


\section{Integration of the predictions of two models with dose measurements in a case study of children exposed to the emissions of a lead smelter}

\section{Abstract}

The predictions of two source-to-dose models are systematically evaluated with observed data collected in a village polluted by a currently operating secondary lead smelter. Both models were built up from several sub-models linked together and run using Monte-Carlo simulation, to calculate the distribution children's blood lead levels attributable to the emissions from the facility. The first model system is composed of the CalTOX model linked to a recoded version of the IEUBK model. This system provides the distribution of the media-specific lead concentrations (air, soil, fruit, vegetables and blood) in the whole area investigated. The second model consists of a statistical model to estimate the lead deposition on the ground, a modified version of the model HHRAP and the same recoded version of the IEUBK model. This system provides an estimate of the concentration of exposure of specific individuals living in the study area. The predictions of the first model system were improved in terms of accuracy and precision by performing a sensitivity analysis and using field data to correct the default value provided for the leaf wet density. However, in this case study, the first model system tends to overestimate the exposure due to exposed vegetables. The second model was tested for nine children with contrasting exposure conditions. It managed to capture the blood levels for eight of them. In the last case, the exposure of the child by pathways not considered in the model may explain the failure of the model. The interest of this integrated model is to provide outputs with lower variance than the first model system, but at the moment further tests are necessary to conclude about its accuracy.

Keywords : Exposure assessment, multimedia models, probabilistic risk assessment, lead, IEUBK. 


\section{INTRODUCTION}

Exposure models for chemicals are used around the world to assess the human health risks and to support regulatory decision making. For example, they are used to support policies for pollution control (Bonnard 2006) such as the Hot Spots Program of California Environmental Protection Agency (OEHHA 2003), in which the risks linked to atmospheric emissions from existing facilities are estimated. They are also used in France for Registered Installations for Protection of the Environment (INERIS 2003), which requires a human health risk assessment study to be performed and included in all the environmental impact analyses for new or modified facilities. Exposure models are also employed to estimate the risks linked to manufactured substances, as required by the European regulation for new and existing substances (EC 2003, 2004). Many countries define safety limits with models for various exposure media such as food, water and air (WHO 1993, 2000 and national regulations), as well for soils, for which human health risk assessment is used to identify, prioritise and assess the need for remedial actions (US EPA, Ferguson 1999).

Because of the critical role played by models, scientists are required to show that their predictions are reliable. Even though a "model can never be truly validated, (but only invalidated)"(Oreskes 1998, NCR 2007), it is still necessary to evaluate its fitness for use. Part of this process is checking if models yield results matching the observations from field studies, and for the right reasons (that is by providing the correct cause-effect relationships between input and output) and capture this link with a sufficient level of precision.

In the context of industrial facilities and contaminated soils, health risk assessment studies employ multimedia exposure models to predict contaminations at a local scale and sometimes employ physiologically based pharmacokinetic (PBPK) models, when the exposure levels need to be expressed in terms of internal doses, as for lead, whose risk management threshold value is usually fixed at $100 \mu \mathrm{g} / \mathrm{l}$ in blood for children.

A number of different multimedia models have undergone empirical evaluation in the last decade, but these exercises were carried out at regional or continental scales (Schwartz 2000) and most of the time, they were limited to environmental concentrations (Kawamoto and Park 2006, Armitage et al. 2007, Luo and Yang 2007). In the case of the PBPK models, results have been evaluated with subjects in controlled conditions where there were either administrated doses or measured environmental concentrations (Cohen et al. 1998, Hogan et 
al. 1998, Griffin et al. 1999, Biesiada et al. 1999, Glorennec et al. 2007a), but none of these studies have tracked multimedia transport from a contamination source. Because of the difficulties in collecting for the same period and the same location sufficient data for the source emissions, environmental concentrations, activity patterns, biomonitoring data, and reconstructing past exposures, predictions of multimedia models have seldom been compared with biomonitoring data from the source of contamination. Such an analysis was conducted in a case of contaminated soils by polycyclic aromatic hydrocarbons (Dor et al. 2003), where urinary 1-hydroxypyren data collected from workers were compared to the levels predicted by several multimedia models. That study showed discrepancies among the models tested, in terms of magnitude of the output and of predominant exposure pathways. However, the authors carried out comparisons using a deterministic approach with a point estimate obtained from the different models. Because they did not know the precision of those point estimates, they could not determine to what extent these point estimates were truly different or even comparable.

The goal of this paper is to evaluate the performance (accuracy and precision) of two sourceto-dose modeling approaches, for a contaminated site by a secondary-lead smelter. Lead contamination was selected because lead is a contaminant often considered in health risk assessments for industrial sites. At such sites, lead can be found in various exposure media, a situation that requires consideration of multiple exposure pathways and provides the opportunity to assess exposure levels both by modeling and measuring blood lead. The comparison of lead measurements and lead modeling results can be carried out at several levels: first in environmental media (such as air or soil), second in exposure media (such as vegetables) and lastly in the human body. The intermediate points of comparison help to determine at which level discrepancies may appear between models and observations and whether the final results are correct for the right reasons. With this approach, one strives not only for good agreement between models and observations (exposure model predictions versus biomarker data) but uses the intermediate steps to confirm consistent hypotheses regarding the magnitude and variation among competing exposure pathways.

\section{METHODS}

The lead smelter is located in a French village. The local authorities have ordered many investigations in this village and have implemented a control of the environment media concentrations for several years. The data available were collected in order to carry out the 
model evaluations and several campaigns of measurements were performed to complete the dataset.

Two source-to-dose models, built-up from existing sub-models, were used for this study and run simultaneously by Monte-Carlo sampling from the ranges of parameter input values.

The data related to the site and the models used are presented in the following subsections. The data not shown (measurement data and input parameters of the models) are detailed in a report available upon request(Bonnard 2008).

\section{Study Village and Lead Emissions}

The village has about 800 inhabitants. The facility producing lead began operations in 1970 . It recycles lead from engine-batteries. In relation to the facility, houses are located in a sector between the north-north-east axis to the south-west axis, with the major portion of them been located between the north-east and the south-east axes. The distance from the facility stacks ranges from 100 meters to $1 \mathrm{~km}$. Currently, this smelter is the only facility in the village emitting lead in the atmosphere. From 2000 to the end of 2001, several measures were implemented to reduce the contamination linked to its activity. These measures resulted in a significant reduction of the atmospheric emissions of lead.

\section{Child Biomonitoring Data and Exposure Survey}

A biomonitoring campaigns for children's blood lead was carried out in this village in June 2002 by the local health administration. A questionnaire was filled out for each child at that sampling time to collect information on his or her exposure conditions. The questionnaire documented age, residence time in the village, places frequented, age of the home, proportion of fruit and vegetables consumed from the family garden, type of water (tap or bottled) consumed, and parents' place of work.

To protect the confidentiality of the children, we were not able to obtain the exact location of the house where each child dwelled. Only the distance to the facility was provided, with an indicator, going from 1 to 3 , expressing the propensity of the wind blowing from the facility towards the child's house. In addition, a map was provided to us indicating three different sectors assigned a wind propensity value equal to 1 , three others a value of 2 , and two sectors a value of 3 . 
Among all the children likely to be exposed, $67 \%$ took part into the study, namely 97 children. Among them, 19 had parents working in the facility. Because the local sanitary authorities have demonstrated a positive link between the children's blood lead and the parents working in the facility for this sample of data (Schmitt et al 2002) and since no multimedia exposure model is currently able to take into account such a relationship, we only kept the lead blood data from the 78 children whose parents did not work in the facility.

\section{Environmental Media Measurements}

\section{Air concentrations}

Daily air concentration data are collected from ATMO Champagne (2002), a public association in charge of monitoring the air quality. An air sampler, measuring PM10, was placed in the village at 120 meters from the facility stacks. Air concentrations were measured by atomic absorption spectrometry (AFNOR, 1990).

\section{Plant concentrations}

A monitoring program has been conducted by a private company. Each year, it consists of the collection of about 20 samples of fruit or vegetables, from 6 or 7 volunteers' gardens, located between 80 to 600 meters from the facility. All the samples are prepared and washed before being analysed (Prost 2002-2005).

\section{Deposition to the ground surface}

A campaign was conducted to measure monthly lead deposition on the ground at 15 locations in the village, using deposit gauges (ISO 1989). These measurements were made in October and November 2005. One duplicate device was used to check the reproducibility and 7 of the samples collected were distributed on the North-East axis relating to the facility, which corresponds to the preferential wind direction. The results of this measurement campaign, as reported in Bonnard (2008), showed a clear decreasing level of deposition with the distance.

\section{Soil concentrations}

Several campaigns of soil lead concentration measurements have been performed in the village since 1998. However, because of the location and the depth of the samples, few data could be considered as representative of the population exposure. Thus, there were two 
additional measurement campaigns in the summer of 2006. The first consisted of 48 surface soil samples and 12 samples taken from the first 20 centimeters. All were composite samples assembled by mixing five sub-samples from the same area. The samples were not distributed according to a regular grid but taken in the village from locations close to dwellings and selected according to accessibility. The surface samples were collected in open areas and in the inhabitants' gardens, where the soil had not been disturbed. All of the the first-twentycentimeter samples came from the inhabitants' kitchen gardens. The soils were digested by aqua regia and analysed by inductively coupled plasma optical emission spectrometry (ICP/OES) according to the European standard analytical method (ISO 1996, CEN 2000). The second campaign consisted of in-situ measurements made with a portable X-ray fluorescence device. Measurements were performed at 133 locations. In order to evaluate correlation of results between the two methods, some of the fluorescence measurements were made at the location where soil surface analytical samples were collected and 24 additional measurements by X-ray fluorescence were performed on soil samples prepared at the laboratory for extraction before ICP/OES analysis. During the program that monitored lead in vegetables cultivated by inhabitants, measurements of lead in the first twenty centimeters of soil were performed. They were added to our database. A geostatistical study, with a set of 156 data corresponding to the lead concentration in the surface soil and with a set of 39 data corresponding to the first-twenty-centimeter soil samples, was achieved.

Lead is characterized by a low mobility in soils and tends to accumulate in the surface layers (Adriano 1986, Kabatia-Pendias 1992, Alloway 1995). However, even if the quantities of lead collected in each gauge during our two-month-measurement campaign (while the stack emissions were higher than the 2002 to 2006 average ones) had been deposited on the ground for four years (between 2002 and 2006) and had not moved, that deposition of lead would correspond to an increase of the concentration in the first two centimeter layer of less than $5 \%$. Given this low accumulation rate, we assumed that the values measured in the soils in 2006 are representative of the concentrations in 2002. Subject to the condition that no other source was added to the soils and the surface soil was not mixed with other soil layers, this assumption seems reasonable.

\section{Source to Dose Modeling}

Source to dose modeling was carried out with two alternative integrated models. Both of them link a multimedia fate model with a pharmacokinetic model. The first integrated model 
is process based and its purpose is to provide a regional mass balance to track lead from a source to receptor using generic parameters. The second model uses an empirical relationship to estimate the lead deposition on the ground and is intended to be both site and receptor specific.

\section{Description of integrated model A}

Model A consists of the CalTOX multimedia fate and multi-pathway exposure model (Mckone 1993, 2002) integrated with the exposure-uptake-biokinetic (IEUBK) model (US EPA 1994, White et al 1998). We set up this model system in EXCELC files, and ran probabilistic assessments with the software Crystal Ball(Decisoneering 2005).

CalTOX is a fugacity-based mass balance model in which each environmental medium (air, soil, water, etc) is represented by a homogeneous compartment. IEUBK is the model recommended by the United States Environmental Protection Agency (US EPA) to estimate children's blood lead exposure. It permits calculation of the lead intake and uptake from the exposure media concentrations and then determines the blood lead levels using a biokinetic sub-model. To address the inability of IEUBK to propagate uncertainty and variability from lead intake, Syracuse Research Corporation developed the Integrated Stochastic Exposure (ISE) model (SRC, 2003) using the same conceptual model as IEUBK but allowing for stochastic simulations. We did the same, by developing our own version of IEUBK using EXCELC and Visual Basic, so that we could link it directly to the stochastic outputs of CalTOX. We checked that our implementation of IEUBK gives exactly the same results as the original code. With this approach our blood lead prediction model could consider temporal variation of lead intake and probabilistic distributions for some inputs defined as point estimates in the ISE model.

We accounted for intake of lead through inhalation, soil ingestion, ingestion of local fruits and vegetables, and background exposure from non-local food consumption (Glorennec 2007b).

Based on atmospheric emissions and the distribution of lead concentrations measured in the first twenty centimeters of soil, model A was used with Crystal Ball to characterize the distributions of lead in the village air, in the surface soil, in the above-ground fruits and vegetables and the below-ground vegetables grown in the village, and finally in the blood of the children of the village. 


\section{Description of integrated model B}

Model B has three components: (1) a regression model that calculates lead deposition according to the location of the household in the village, (2) a multimedia exposure model that calculates local lead concentrations in environmental and exposure media based on the deposition rate, the surface soil concentration and the soil concentration in the first twenty centimeters and (3) our version of IEUBK recoded in EXCELC.

Model B was built to estimate lead exposures for precise locations, an approach often required for contaminated sites to distinguish the areas requiring remediation from those which do not. Unlike model A, which is aimed to capture the distribution of the concentrations over the whole village, model B enables to represent the exposure of individuals. Because the exact location of each child's house was not known, we had to identify it basing on the concordance among three sources of information: (1) the child's distance from the facility, (2) the sector where the house was located and (3) a bird's-eye view zonal map of the village. In some cases, only one location of household corresponded to information derived from these three sources, in other there were several possibilities. Because of this difficulty, blood lead level was modeled for a subset of nine children for which we had identified only one or two possibilities of housing location. If there were two possible locations for one child's house, two predictions were made for that child's blood lead based on a different soil concentration and a different lead deposition on the ground. The children of this subset had contrasting exposure conditions (high, low or no consumption of home-grown vegetables, close or far from the facility, low or high blood lead level) (Table 1).

We use the regression model in place of a classical gaussian air dispersion model because we found the accuracy of these models, which predict deposition and air concentration, at each point of a grid, to be inappropriate in regards of the estimation of fugitive emissions (see section called Source term definition). Instead we fitted deposition data collected during the sampling campaign (see section called Deposition to the ground surface) using a statistical relationship, taking into account the distance $\left(D_{i}\right.$ in meters) of a specific location $i$ from the facility, the frequency ( $\mathrm{W}_{\mathrm{ij}}$ unitless) of the wind blowing from the facility towards a specific location during month $j$ and the magnitude of stack emissions ( $E_{j}$ in $g /$ month). We used Statistica (Statsoft 1999) for this analysis. We obtained the higher correlation coefficient and the lower residual standard deviation with the following equation by ordinary least squares:

$$
\hat{\mathrm{Y}}_{\mathrm{ij}}=\log \operatorname{dep}_{i j}=0.35-1.7 \times 10^{-3} D_{i}+1.31 W_{i j}+1.4 \times 10^{-5} E_{j} \quad\left(\rho^{2}=0.93\right)
$$


where $\operatorname{dep}_{i j}=$ total deposition of lead on the ground at location $\mathrm{i}$ during month $\mathrm{j}$ (in $\left.\mathrm{mg} / \mathrm{m}^{2} / \mathrm{month}\right)$.

We used a Student's T-test to test if a coefficient of this relationship is significantly different from zero. Although the equation above is based on data collected for only two months, all coefficients were found to be statistically significant. In a good regression model, residuals (difference between the observed values and the predicted values) are normal and homoscedastic (residuals have the same variance). The residuals of the above equation appeared normal and homoscedastic.

We characterized the uncertainty of the predicted deposition $(\hat{Y})$ using a Student's distribution, with 26 degrees of freedom, multiplied by the estimated deviation of $\hat{Y}$ (Foucart 1997). We have 26 degrees of freedom because we have 30 data to define a relationship that has 4 coefficients. The estimated deviation of $\hat{Y}$ is a $\mathrm{T}$ distribution based on the residual estimation error from the regression model. The output of this relationship along with the error were used as inputs in the multimedia exposure model.

The media concentrations were calculated from the equations described in the Human Health Risk Assessment Protocol (HHRAP) document (US EPA 2005). However, a supplemental soil layer (between 0 to $10 \mathrm{~cm}$ from the surface) for predicting the forage contamination from soil and additional classes of plants (fruit, leafy vegetables and fruit vegetables) were introduced, as well as equations for plant contamination by irrigation and deposition of resuspended soil particles. The equations used for these pathways are those given in the model ERMYN (US DOe 2003a). The concentrations in air, surface soil and plants yielded by the multimedia exposure model were used as input of the new version of IEUBK to obtain the child blood lead distributions.

\section{Values used for model parameters and inputs}

Here we describe how we obtained model inputs. First we consider the period for which we had to model the doses adsorbed by children to estimate their blood lead level at the time of the biomonitoring campaign. Next we consider the case of source terms, lead chemical properties, environmental parameters, intake and uptake parameters. We developed probability distributions for each input parameter of both models. 


\section{Period for reconstructing children's intake}

The half-life of lead in blood is estimated to be one month. Although lead is also stocked in bones and slowly released in blood from there, it has been shown that a reduction of child exposure brings out a rather fast reduction of the blood lead (Declercq and Ladrière 2004, Khoury et al 2003). The conceptual model implemented in the IEUBK software also yields a rapid reduction of the blood lead, once intake is stopped. We ran the IEUBK model for the case of a child with a cumulative ingestion dose 3 times higher than the estimated background intake in France for 3 years and then a dose equal to the background intake (Glorennec 2007b). We found that one year after reducing the intake, the blood lead would be only 2 percent higher than the one calculated with the background intake for 4 years. Therefore, the efforts to reconstruct the intake doses were focused on a period starting from spring 2001 to the date of the campaign of blood lead measurements. Beforehand, the exposure conditions were assumed to be the same as those between January and June 2001 .

\section{Source term definition}

\section{$\underline{\text { Model A }}$}

A lognormal distribution was fitted to the observed lead concentrations in the first twenty centimeters of soil using a Z-plot chart. The resulting distribution with an arithmetic mean of $261 \mathrm{mg} / \mathrm{kg}$ and a standard deviation of $249 \mathrm{mg} / \mathrm{kg}$ was assigned to the root zone soil concentration parameter of CalTOX.

We estimate smelter stack emissions from monthly sampling of particule emissions, the measurement of the lead concentration in the emitted particles and the duration of operation. The smelter operators try to limit the fugitive emissions by keeping the pressure inside the buildings lower than the outside pressure, washing outdoor surfaces daily and stocking raw materials products and by-products indoors. Nevertheless, preliminary calculations performed with an air dispersion model (CERC 2000) showed that the air concentrations and particle fallout recorded downwind could not be explained purely by the recorded stack emissions (Bonnard 2008). Therefore, we had to include fugitive emissions. We estimated them using three methods (inverse modeling, predictions based on the emission factors and the production rate, and a calculation based on the indoor air concentration in the buildings of the factory and the ventilation rate) and obtained consistent estimates. With inverse modeling, we calculated the volumetric flux required to get the best correlation between the air dispersion model and the lead deposition measured during the campaign conducted in October and 
December 2005 and obtained a fugitive emissions estimate between 20 and $60 \mathrm{~kg} / \mathrm{month}$. Emissions factors for this type of facility and information on its production rate give fugitive emissions between 25 and $73 \mathrm{~kg} /$ month. Data on lead concentration measured in indoor air of the facility building with an assumption of a ventilation rate of 10 times per hour give a fugitive emissions estimate of $34 \mathrm{~kg} /$ month.

To cover the whole growing period of the local fruit and vegetables consumed till the date of the campaign of blood lead measurements, stack lead emissions were estimated from the data recorded from April 2001 to June 2002. As information on fugitive emissions is poor, a triangular distribution was assigned to the total atmospheric emissions from the estimates obtained for the stack and the fugitive emissions during this period. The mode is equal to $1,200 \mathrm{~g} / \mathrm{d}$, the minimum to $750 \mathrm{~g} / \mathrm{d}$ and the maximum to $2,800 \mathrm{~g} / \mathrm{d}$.

For comparing the predicted vegetation concentrations with the observed ones, the emissions were estimated over the vegetation exposure period to fallout from the facility (from April to July, in 2002 to 2005). The total atmospheric emissions were defined by a triangular distribution with a mode of $780 \mathrm{~g} / \mathrm{d}$, a minimum of $450 \mathrm{~g} / \mathrm{d}$ and a maximum of 1,450 g/d.

\section{$\underline{\text { Model B }}$}

Spatial soil mean concentration in the land associated to each child's house was estimated by kriging. Cumulative distributions were defined for the surface soil and the root-zone soil owing to the turning band method (Chilès 1999, Bonnard 2008).

The atmospheric emissions were estimated from the statistical model described above (Equation 1) for each location and period used to represent the atmospheric deposition on the different kinds of home-grown plants.

\section{Chemical properties for lead}

\section{$\underline{\text { Model A }}$}

With the exception of the particle-water partition coefficients, we used the default distributions provided by CalTOX for chemical properties-water solubility, partition coefficients, and bioconcentration factors. We found that the particle-water partition coefficient $(\mathrm{Kd})$ in CalTOX was high relative to ranges found in other papers. Since $\mathrm{Kd}$ for lead is known to depend on the soil $\mathrm{pH}$, we used the recommendations from the Office of Air and Radiation (US EPA 1999) and the $\mathrm{pH}$ values collected in the garden soils of the village to define a triangular distribution. The measured $\mathrm{pH}$ going from 5.3 to 8.3 , the minimum and 
maximum values for the closest ranges of soil $\mathrm{pH}$, given by the Office of Air and Radiation, were used as minimum and maximum of the distribution $(150 \mathrm{~L} / \mathrm{kg}$ and $23,279 \mathrm{~L} / \mathrm{kg}$ respectively). The mode was assigned a value of $1731 \mathrm{l} / \mathrm{kg}$, which was calculated from the modal value of measured $\mathrm{pH}$ and the Office of Air and Radiation's relationship between lead $\mathrm{Kd}$ and $\mathrm{pH}$.

\section{$\underline{\text { Model B }}$}

The parameters required for model B are the soil-plant transfer coefficients. To obtain values, we made a review of the primary literature and fitted the resulting dataset of selected values to a lognormal distribution (Table 2, Bonnard 2008).

\section{Environmental parameters}

\section{$\underline{\text { Model A }}$}

For model A we used the default distributions provided by CalTOX for all environmental parameters except area, rainfall, wind speed, and temperature. We replaced distributions for these parameters in CalTOX by local data. In addition we replace the CalTOX root zone soil depth with a mean value equal to $0.2 \mathrm{~m}$ to be consistent with the measured data for the village.

\section{Model B}

Most of environmental parameters required in model B are different from those of CalTOX. They mainly concern the description of the various categories of plants. Distributions were defined from the literature (Table 2, Bonnard 2008).

\section{Intake parameters}

From birth to the age of 7 , we defined plant consumption and lead exposure from local food consumption for seven age classes based on French surveys (Boggio et al. 1999, Volatier 2000).

For soil ingestion, we used the cumulative distribution provided by ISE with a median equal to $135 \mathrm{mg} / \mathrm{d}$ (US EPA 1994, 1999). We note that other distributions with lower median values were available from empirical data published by Thompson et al. (1991) and Stanek et al. (2000, 2001). However, the IEUBK model was calibrated with a point estimate equal to 135 $\mathrm{mg} /$ day. On the other hand, the lognormal distribution given in the ISE's model for soil ingestion, has a standard deviation that appears too low relative to what is available in the literature. For example, the ratio of the $95^{\text {th }}$ percentile to the $5^{\text {th }}$ percentile in the ISE 
distribution is less than 2 , indicating almost no inter-individual variability. We did use the ISE age-specific weighting factors for soil ingestion in our recoded version.

For model B, we use observed individual data for each child from the study population to obtain the age, the seasonal variation in the percentage of home-grown fruits and vegetables consumed, and the date of moving into the village.

\section{Uptake parameters}

The bioavailability of lead in food and the relative bioavailability of lead in soil were revised to better reflect data documented in IEUBK for these factors.

The range reported by the USEPA in the IEUBK guidance (US EPA 1994) for absorption of lead from diet is 42 to $53 \%$. These values correspond to the $40^{\text {th }}$ and $63^{\text {th }}$ percentiles of the lognormal distribution defined in the ISE model for this parameter (mean $=0.5$, standard deviation $=0.2)$. A lower value was used for the standard deviation $(0.05$ instead of 0.2$)$ to get a distribution more in accordance with the range of data given above (in these conditions, the low and high values given by the US EPA correspond to the $5^{\text {th }}$ and $75^{\text {th }}$ percentiles of the new distribution defined for absorption of lead from diet).

For the absolute bioavailability of soil lead, ISE gives a point estimate of 0.3 , but no distribution is defined. We used the values collected by Ruby et al. (1999) for lead uptake from soils (data from wastes and mines were eliminated), to define a normal distribution with a mean equal to 0.6 and a standard deviation equal to 0.2 for the relative biovailability of soil lead. The mean of the soil lead absolute bioavailability obtained is then close to the point estimate used in the IEUBK and ISE models.

\section{Probabilistic computation}

All of our calculations were based on Monte Carlo simulations using 5000 runs with latinhypercube sampling. We used the Monte Carlo results to develop cumulative probability distributions that can be compared to cumulative distributions of measured concentrations in the media. 


\section{RESULTS AND DISCUSSION}

\section{Model A}

Because no significant statistical relationship between the blood level and the age could be identified (Schmitt et al. 2002), we analysed the model's output as the mean of the blood lead from 6 months to 7 years old.

Figure 1 shows the probability plot charts for the (base 10) logarithms of the observed and predicted concentrations in the different exposure media. On these charts, concentrations in the $\mathrm{y}$-axis are represented against the cumulative probability expressed as the number of standard deviation from the geometric mean. For blood lead, figure 1e shows the concentrations calculated by the integrated model and those predicted with the new version of IEUBK from the measurements performed in the samples of surface soil, fruit and vegetables collected in the village.

The observed values in air, ground soil, exposed produce and blood lead tend to follow lognormal distributions. However, concentrations above $500 \mathrm{mg} / \mathrm{kg}$ in the ground soil deviate from a lognormal distribution (these values correspond to a small area close to the facility and without dwelling). The distributions of the calculated concentrations in air and ground soil also follow lognormal distributions, whereas the distributions of the predicted concentrations for the protected produce, the exposed produce and in particular for the blood lead are characterized by two different slopes, indicating bimodal distributions.

Except for the exposed produce, the median values predicted by the integrated model are in good agreement with the observed medians. The predicted median-to-observed median ratios are between 0.5 and 1.3 for these media. But for the exposed produce, the ratio is equal to 18 . Regarding distributions, the observed data for ground soil are well captured until $500 \mathrm{mg} / \mathrm{kg}$. The ranges of the observed and predicted values for the air concentrations are close and the two distributions are quite similar. But for protected produce, the distribution of the observed data is underestimated and above all the distribution of the observed concentrations for exposed produce is overestimated. For blood lead, the variability of the calculated concentrations is higher than that of the observed concentrations. In the case of concentrations predicted from the measurements performed in the exposure media, blood lead concentrations are underestimated up to the $90^{\text {th }}$ percentile, then they are overestimated. The 
values predicted from the integrated model are higher and the difference between the two distributions of calculated concentrations increased with percentiles.

According to figure 2, even though emissions are primarily to air, inhalation of smelter emissions is not a major exposure pathway, because most of the lead emitted to air deposits to soil and from there is transferred to the children by various ingestion pathways.

When blood lead level is predicted from the exposure media concentrations, soil ingestion appears as the predominant pathway in the upper percentiles of the distribution of the predicted blood lead concentrations, as in former studies conducted near smelters (Roels 1980, Gulson 1994, Landrigan 1996). However, when blood lead level is calculated by the integrated model, the ingestion of exposed produce appears as the main pathway in the last quarter of the blood lead distribution. Therefore, the overestimation of the exposure produce concentrations by the integrated model contributes to the overestimation of the upper part of the distribution of blood lead concentrations calculated by this model.

Analysis of the contributions to exposed produce contamination showed that in the first part of the distribution, transfer from air and from surface soil to plants are higher than transfer from root-soil, and then the situation is reversed. In order to understand the reasons for the overestimation of the exposed produce concentrations, we carried out a sensitivity analysis with Crystal Ball. The parameters with the highest contributions to the variance are listed in Table 3 in descending order.

The distributions of the first two parameters with the highest sensitivity (particle-water partition coefficient and root-soil concentration) were defined by taking into account specific data from the studied site. The third parameter is the leaf wet density (rho_leaf). The default value, which was used in the computations, is equal to $820 \mathrm{~kg} / \mathrm{m}^{3}$. With a volume fraction of water in leaf (beta_leaf) equal to 0.5, as provided in CalTOX, we get a value of 0.61 for the mass water fraction $(0.5 \times 1000 / 820)$, whereas the data for the exposed produce (leafy vegetables) collected in the gardens ranged from 0.77 to 0.98 . So, we determined a new value for the leaf wet density on the basis of the mean of the leaf mass water fraction measured in the collected samples of exposed produce $(0.91)$. We found a value equal to $550 \mathrm{~kg} / \mathrm{m}^{3}$. It remains in accordance with the typical values used in models for leaf wet density, which are comprised between 500 and $900 \mathrm{~kg} / \mathrm{m}^{3}$ (Riederer 1990, Paterson et al. 1991, Bacci et al. 1992, Trapp and McFarlane 1994, Maccrady and Maggard 1995). 
As a result, the distribution obtained for the exposed produce concentrations (figure 3a, curve 3 ) is closer to that of the observed concentrations. The predicted concentrations were divided nearly by a factor 2, except at the lower tail of the distribution. The air, soil and protected concentration distributions were not altered by this change, but the variance in the predicted blood-lead concentrations (calculated by the integrated model from the predicted concentrations in produce) was reduced (figure $3 b$, curve 3 ).

For the other parameters pointed out in the sensitivity analysis, we found no new data justifying any modifications of the default values and significantly improving the prediction of the exposed produce concentrations.

But, we needed to consider that fruits and vegetables had been washed before the analyses and recognized that the impact of washing is not considered in the model. Unfortunately, the extent to which such a treatment reduces the contribution of air deposition and rain-splash to fruit and vegetables contamination is not well known. In our model, if the contributions of both these pathways are divided arbitrarily by ten, it appears clearly that the lower part of the predicted distribution (figure 3a, curve 4) is closer to that of the observed concentrations data. That means that the variability of the measurements is then captured better by the model. The model over-predicts the concentration in exposed fruits and vegetables by a factor 4 at the median, under these assumptions. The distribution of the blood lead concentrations predicted from the integrated model is then very close to that predicted by the new version of IEUBK from the exposure media measurements (figure $3 b$, curves 4 and 5).

Nevertheless, these two distributions still deviate from the distribution of the observed blood lead at the upper percentiles and according to the integrated model, the ingestion of homegown plants remains the main contributor to the blood lead level above the $90^{\text {th }}$ percentile. This is not in accordance with the result of the univariate analysis of observed data showing a higher mean of blood lead concentration for no consumers of homegrown plants $(\mathrm{m}=65 \mu \mathrm{g} / \mathrm{l}, \mathrm{n}=46)$ than for consumers $(\mathrm{m}=45 \mu \mathrm{g} / \mathrm{l}, \mathrm{n}=32)$, even if for the group of homegrown plant consumers, the blood lead level increases with the fraction of homegrown plants in the diet. The discrepancy between observed and predicted data may be due to the fact that in the sample of children tested, those with the highest consumption of kitchen garden foods were those living the farthest away from the facility, thereby with the lowest lead concentrations in plants. In other words, the actual consumption of home-grown produce in the village and its contribution to blood lead level at the upper percentiles is overestimated 
by the model, which assumes a homogeneous distribution of the home-grown produce consumptions within the village.

\section{Model B}

The results of model B are provided in Figure 4 for nine children with one or two possible housing locations. We can see that the measured blood lead levels are between the $5^{\text {th }}$ and the $95^{\text {th }}$ percentiles of the model results, with the exception of child 43 . The measured blood-lead levels correspond to various percentiles of the distribution given by the model, going from the $25^{\text {th }}$ to the $88^{\text {th }}$ percentile according to the different children. Measured values of blood lead above the predicted median ratios are between 0.7 and 1.7 (excluding the results corresponding to child 43).

Model B was able to capture the blood-lead-level ranges for the various conditions tested, except for child 43. The discrepancy between the model output and the blood lead level measured for this child may be explained by the fact that this child lived in an old house built before the ban of lead for interior paint. The univariate analysis of the data of the child biomonitoring and of the exposure survey showed a higher mean of blood lead concentration for children living in houses built before 1948 than for children living in more recent houses (DDASS 2002). But, this exposure pathway is not taken into account by the model.

It has to be noted that using either the Thompson et al. (1991) or Stanek et al. $(2000,2001)$ distributions for soil ingestion, instead of a distribution centered on the value used to calibrate IEUBK for soil ingestion, results in lower estimates of blood lead concentrations, especially when the soil ingestion is a significant contributor to overall exposure. For example soil ingestion dominates when the children consume few or no homegrown foods, and when the soil lead concentration is high. In the sub-sample tested here, the geometric mean of the measured median above the calculated value ratio would increase from 1.1 to 1.3 , if the distribution used for the quantity of soil ingested was replaced by Thompson et al.'s distribution and it would reach a higher value with Stanek et al.'s distribution.

Many studies showed a correlation between blood lead level and soil lead (Xintaras 1992, Landrigan 1996, Mielke et al 1998). However, for instance, for child 71, who did not consume kitchen garden plants and who lived close to the facility, model B indicates that exposure due to ingestion of no local food is slightly higher than exposure due to soil ingestion. This is certainly due to the fact that soil lead concentration at the location of his 
house is not high (200-230 mg/kg) compared to values measured in these studies. For child 28 , who ate a large amount of home-grown plants and lived relatively far from the facility, the ingestion of homegrown produce appears as the largest contributor to the blood lead level. Wilhem et al. (2005), who studied the dietary intake of lead by two groups of children living in an industrial region, found no difference between those eating a large part of produce from the families own vegetable garden and those consuming exclusively food from the supermarket. But in this case, comparison was made at a region scale without an identified local source of lead. Here, measures of concentrations in plants from child 28's garden would be necessary to confirm the role played by the ingestion of homegrown plants.

The uncertainties in the modeled blood lead predictions for model B are reflected by the ratios of the $95^{\text {th }}$ percentile to the $5^{\text {th }}$ percentile, which are between 2.6 and 4.9. The widest $90 \%$ interval is given for child 28. In this case, the root soil concentration is the highest contributor to the variance. This high contribution is due to a lack of precision in the estimation of the root soil concentration in the child's living area. Increasing the sampling efforts in soils of the farthest areas of the village could permit the reduction of the overall uncertainty. Nevertheless, model B is able to predict blood lead distributions with lower variance than model $\mathrm{A}$ (the ratio of the $95^{\text {th }}$ percentile to the $5^{\text {th }}$ percentile is equal to 10.2 with model A). Indeed, model A has to integrate inter-individual variability in the input distributions, while model B took it into account by a better description of the influence of the distribution of lead deposition and individual characteristics.

\section{Limitations of the comparison between predicted data and observed data}

Finally, we acknowledge that the exercise of comparison made with both models may be limited by the quality of data used to perform it.

Soil lead concentration appeared as the most sensitive parameter for the blood lead predictions performed. However, it was measured in bulk soil and not in the finest particle fraction, more likely representative of lead concentration in soil ingested by children. Campaigns for soil lead and blood lead concentrations were not conducted at the same time. (so, there is a possibility that soil was moved in some areas of the village between the two campaigns) and soil lead was not measured in children's garden soil, but estimated by a geostatistical study. Air emissions used in model A were also estimated from indirect methods. 
On the other hand, the lack of measurement data in the village for tapwater and lead bioavailability, which is usually recognized as a determining factor for estimating blood lead level (Mushak 1998), should not represent a major fault. For drinking water, the analysis of observed data showed that there is no significant difference between blood lead level of children drinking tapwater and those drinking bottled water. Lead bioavailability is not either a very sensitive parameter in the previous calculations. The absolute lead bioavailability and the relative bioavailability of soil lead together contribute to $3 \%$ of variance in model $\mathrm{A}$ and to $7 \%$ in model $\mathrm{B}$ at the maximum.

\section{CONCLUSIONS}

Both models, built for estimating human health risks linked to future emissions of facilities, may provide useful insight regarding source-to-dose relationships for the exposure population. Model A may be used to address general trends and model B is more focused on capturing individual exposures. In considering the results presented above, there is an issue that cuts across our evaluation of the individual models and data. In this process, we recognized that not only did we gain insight into the two models, but by making a systematic comparison of two models with a specific case study, we gained important insights about lead exposure in these communities that could not be obtained from either model or the environmental/biomonitoring data used in isolation. Thus we conclude that using the two models together with population and site-specific measurements of blood lead and environmental conditions provides for this population's lead exposure patterns a level of understanding that could not be achieved with either model alone or with just the blood surveillance measurements.

Model A provides an ability to capture the distributions of lead in the media and the blood lead concentrations at a local scale. It offers the opportunity to identify the potential pathways of concern and to characterize also the distribution of the exposure level. From the initial results of the model, mainly used with default values, the information from the sensitivity analysis and the pathway contributions evaluation help to identify the parameter improvements needed to calibrate the model to this case. However, predicted concentrations in exposed vegetables may be a potential source of overestimation of blood lead level.

Model B provides outputs that can be targeted to specific areas and exposure conditions. It was set up to answer some questions, such as "in which zones or from which distance may the consumption of home-grown produce raise a health concern ?" Because of this feature, 
model B can predict blood lead distributions with lower variance than model A. Precision of assessment is important for discriminating those situations that require management measures from those which do not, especially if the risk management threshold is low. Although, the results provided by model $\mathrm{B}$, for contrasting exposure conditions, are in accordance with the measurements (apart from a case that may involve an exposure pathway that is not considered in the model), the low number of cases tested here does not enable to conclude on the performances of model B at the moment.

\section{ACKNOWLEDGEMENTS}

The authors thank the local administration (Direction Régionale de l'Industrie, de la Recherche et de l'Equipement de Champagne-Ardennes and Direction Départementale des Affaires Sanitaires et Sociales des Ardennes), the director's facility, ATMO Champagne and the company Gestion des sites et des sols contaminés (GSC) for communicating their data, as well as the studied village inhabitants who permitted us to take samples from their garden and the mayor for his help. We also thank F. Bois of Institute of Industrial Environment and Risks for his review of the paper and M. Sohn of Lawrence Berkeley National Laboratory for his guidance and input on this work. R. Bonnard's work was supported by the French Ministry of Ecology and Sustainable Development (Budget Civil de la Recherche et du Développement, grant BRCD-03-DRC-06). T. McKone was supported in part by the US Environmental Protection Agency through Interagency Agreement DW-988-38190-01-0 carried out through the US Department of Energy contract Grant No. DE-AC02-05CH11231. McKone was also supported by Cooperative Agreement Number U19/EH000097-03 from the US Centers for Disease Control and Prevention (CDC).

\section{REFERENCES}

Adriano DC. 1986. Trace elements in the terrestrial environment. Springer, New-York, USA

AFNOR, NFX43-026. 1990. Qualité de l'air, Air ambiant, Détermination du plomb dans les aérosols, spectrométrie d'absorption atomique

Alloway BJ. 1995. Heavy metals in soils, second edition. Blackie. Academic \& Professional, London, United Kingdom

APRIFEL (Agence fruits et légumes frais). 2008. Les fiches nutritionnelles par produit, http://www.aprifel.com/fiches, produits, liste.php 
Armitage J, Cousins I, Hauck M, Harbers J, Huijbregts M. 2007.Empirical evaluation of spatial and non-spatial European-scale multimedia fate models: results and implications for chemicals risk assessment, Journal of Environment Monitoring, 9: 572-581

ATMO-Champagne. 2002. Activity reports and publications available at http://www.atmoca.asso.fr

Bacci E, Cerejeira M.J, Gaggi C, Vighi M. 1992. Chlorinated dioxins - Volatilization from soils and bioconcentration in plant leaves. Bulletin of Environmental contamination and Toxicology 48: 401-408

Baes C, Sharp A, Sjoreen A, Shor R. 1984. A review and analysis of parameters for assessing transport of environmentally released radionuclides through agriculture, Oak Ridge National Laboratory. USA

Biesiada M, Hubicki L. 1999. Blood lead levels in children: epidemiology vs. simulations. European Journal of Epidemiology 15(5):485-91

Boggio, Grossiord, Guyon, Fuchs, Fantino. 1999. Consommation alimentaire des nourrissons et des enfants en bas âge en France en 1997. Archives Pédiatrique 6: 740-747

Bonnard R. 2006. Estimation de l'impact des rejets des installations industrielles et utilisation de la démarche d'évaluation des risques à l'étranger, 76413/197, INERIS, Verneuil-en Halatte, France

Bonnard R. 2008. Amélioration des méthodes d'estimation prospective des expositions des populations autour des ICPE. BCRD-03-DRC06, DRC-08-57041-14967A. Verneuil-enHalatte, France

CEN, EN 13346. 2000. Determination of trace elements and phosphorus - aqua regia extraction methods

CERC (Cambridge Environmental Research Consultants). 2000. ADMS 3. Documentation available at http://www.cerc.co.uk/software/pubs/ADMS3\%20techspec.htm

Chiles JP, Delfiner P. 1999. Geostatistics : modeling spatial uncertainty. Wiley. New-York, USA

Cohen JT, Beck BD, Bowers TS, Bornschein RL, Calabrese EJ. 1998. An arsenic exposure model: Probabilistic validation using empirical data, Human and Ecological Risk Assessment 4 (2): 341-378

Decisoneering, Crystal Ball 7.2, Professional edition. 2005. Information available at http://www.decisioneering.com/crystal_ball/index.html 
Declercq C, Ladrière L. 2004. Programme de dépistage du saturnisme infantile dans 9 communes du Nord et du Pas de Calais, CLIS Métaleurop, 29 Septembre 2004. France

Dor F., Empereur-Bissonnet P, Zmirou D, Nedellec V, Haguenor JM, Jongeneelen F, Person A., Dab W., Ferguson C. 2003. Validation of multimedia models assessing exposure to PAH - The SOLEX study, Risk Analysis 23 (5): 1047 - 1057

EC (European Commission). 2003. Technical Guidance Document on risk assessment of substances following European regulations and directives, Second edition, European Chemicals Bureau, Italy

EC (European Commission). 2004. European Union System for the Evaluation of Substances 2.0 (EUSES 2.0). Prepared for the European Chemicals Bureau by the National Institute of Public Health and the Environment (RIVM), Bilthoven, The Netherlands. Available via the European Chemicals Bureau, Italy

ECETOC (European Centre for Ecotoxicology and Toxicology of Chemicals). 1992. Technical report $n^{\circ} 40$, Hazard assessment of chemical contaminants in soil. Brussels, Belgium

Ferguson CC. 1999. Assessing Risks from Contaminated Sites: Policy and Practice in 16 European Countries, Land Contamination \& Reclamation 7 (2): 33-54

Foucart T. 1997. L'analyse des données, Mode d'emploi. Presses universitaires de Rennes. Rennes, France

GCNC (Groupe Chimique Nord-Cotentin). 2002. Impact des rejets chimiques, Vol. 2, annexe 4: Bilan des informations disponibles sur les paramètres agronomiques pour le groupe radioécologique Nord-Cotentin. France

Glorennec P, Declercq C. 2007a. Performance of several decision support tools for determining the need for systematic screening of childhood lead poisoning around industrial sites. European Journal of Public Health, 17(1):47-52

Glorennec P, Bemrah N, Tard A, Robin A, Le Bot B, Bard D. 2007b. Probabilistic modeling of young children's overall lead exposure in France: Integrated approach for various exposure media. Environment.Internatrional (33):937-45

Griffin S, Goodrum PE, Diamond. GL, Meylan W, Brattin WJ, Hassett JM. 1999. Application of a probabilistic risk assessment methodology to a lead smelter site, Human and Ecological Risk Assessment 5 (4): 845-868 
GRNC (Groupe Radioécologique Nord-Cotentin). 2002. Analyse de sensibilité et d'incertitude sur le risque de leucémie attribuable aux installations nucléaires du NordCotentin, annexe 1 : Distributions de probabilité des paramètres. France

Gulson BL, Mizon KJ, Law AJ, Korsch MJ, David JJ, CSIRO/D.E.G. 1994. Source and pathways of lead in humans from the Broken Hill mining community; an alternative use of exploration methods. Economic geology : July v. 89, n4 : 889-908

Hogan K, Marcus A, Smith R, White P. 1998. Integrated exposure uptake biokinetic model for lead in children: empirical comparisons with epidemiologic data. Environmental Health Perspectives 106 Suppl 6:1557-67

INERIS (Institut de 1'Environnement Industriel et des Risques). 2003. Evaluation des risques sanitaires dans les études d'impact des installations classées, Guide méthodologique, Verneuil-en-Halatte, France

ISO 11885. 1996. Water quality - Determination of 33 elements by inductively coupled plasma atomic emission spectroscopy

Kabatia-Pendias A, Pendias H. 1992. Trace elements in soils and plants, second edition CRC Press, Boca. Raton, FL, USA

Kawamoto K, Park KA. 2006. Calculation of environmental concentration and comparison of output for existing chemicals using regional multimedia modelling, Chemosphere: 11541164

Khoury GA, Diamond GL. 2003. Risks to children from exposure to lead in air during remedial or removal activities at Superfund sites: a case study of the RSR lead smelter Superfund site. Journal of Exposure Analysis and Environmental Epidemiology. Jan;13(1):51-65

Landrigan PJ. 1996. Lead levels, home dust, and proximity to lead smelters. Pediatrics 97(4):603-4

Luo Y, Yang X. 2007. A multimedia environmental model of chemical distribution: fate, transport, and uncertainty analysis, Chemosphere, 66: 1396-1407

Maccrady JK, Maggard SP. 1995. Uptake and photodegration of 2,3,7,8 tetrachlorodibenzodioxins sorbed to grass foliage. Environmental Science and Technology, 27: 343-350

McKone ET. 1993. A multimedia total exposure model for hazardous-waste sites. Part I-IV. UCRL-CR-111456 . Lawrence Livermore National Laboratory. Livermore, USA 
McKone ET, Enoch KG. 2002. A multimedia total exposure. Spreadsheet user's guide Version 4.0. 47399. Lawrence Berkeley National Laboratory. Berkeley, CA, USA

Mielke HW, Reagan PL. 1998. Soil is an important pathway of human lead exposure. Environmental Health Perspectives 106 Suppl 1:217-29

Mushak P. 1998. Uses and limits of empirical data in measuring and modeling human lead exposure. Environmental Health Perspectives 106 Suppl 6:1467-84

NRC (National Research Council) Committee on Models in the Regulatory Decision Process. 2007. Models in Environmental Regulatory Decision Making. National Academies, Washington DC, USA

OEHHA (Office of Environmental Health Hazard Assessment). 2003. The Air Toxics Hot Spots Program Guidance manual for preparation of health risk assessment, Oakland, USA

Oreskes N. 1998. Evaluation (not validation) of quantitative models, Environmental Health Perspectives 6, supplement 6: 1453-1460

Paterson SD, Mackay D, Gladman A. 1991. A fugacity model of chemical uptake by. plants from soil and air. Chemosphere 23: 539-565

Prost R, Suivi de la qualité des sols et des végétaux autour de l'usine Métal Blanc à BourgFidèle, GSC (Gestion des sites et sols contaminés), campagne 2002, campagne 2003, campagne 2004, campagne 2005, Versailles, France

Roels HA, Buchet JP, Lauwerys RR, Bruaux P, Claeys-Thoreau F, Lafontaine A, Verduyn G. 1980,Exposure to lead by the oral and the pulmonary routes of children living in the vicinity of a primary lead smelter. Envrionmental research, June 22(1) : 81-94

Riederer M. 1990. Estimating partitioning and transport of organic chemicals in the foliage atmosphere system, Environmental Science and Technology 24: 829-837

Ruby M, Schoof R, Brattin W, Goldade M, Post G., Harnois M, Mosby D, Caastel S, Berti W, Carpentier M, Edwards D, Cragin D, Chappel W. 1999. Advances in evaluating the oral bioavailability of inorganics in soil for use in human health risk assessment, Environmental Science \& Technology 33 (21): 3697-3705 
Schmitt M, Deshayes F, Fradet MR, Coquet S, Brun N, Humbert B. 2002. Nouvelle enquête sur l'imprégnation saturnine des enfants de Bourg-Fidèle. DRASS de Lorraine, CIRE Est, DDASS des Ardennes, InVS, France

Schwartz S. 2000. Quality assurance of exposure models for environmental risk assessment of substances. Doctorat thesis. Institute of Environmental Systems Research, University of Osnabrück. Osnabrück, Germany

SRC (Syracuse Research Corporation). 2003. ISE, Biokinetic model for lead, Windows version 1.41.

Stanek E, Calabrese E. 2000. Daily soil ingestion for children at Superfund site, Risk Analysis, Vol. 20, 5: 627-635

Stanek E, Calabrese E, Zorn M. 2001. Soil ingestion distributions for Monte Carlo risk assessment in chidren, Human and Ecological Risk Assessment 7 (2): 357-368

Statsoft, Statistica, Edition 99 for Windows, Kernel version 5.5. Information available at http://www.statsoft.com

Thompson K, Burmaster D. 1991. Parametric distributions for soil ingestion by children, Risk Analysis 11 (2): 339-342

Trapp S, McFarlane J. 1994. Plant contamination: modelling and simulation of organic chemical processes. Springer. Osnabrück, Germany

Tremel-Shaub A, Feix I. 2005. Contamination des sols. Transferts des sols vers les plantes, EDP Sciences / ADEME. Paris, France

US DOe (US Department of Energy). 2003a. Biosphere model report. MDL-MGR-MD000001 Rev00. Office of Civilian Radioactive Waste Management. USA

US DOe (US Department of Energy). 2003b. Soil-related input parameters for the biosphere model. Office of Civilian Radioactive Waste Management. ANL-NSB-MD-000009 Rev00. USA

US DOe (US Department of Energy). 2003c. Environmental transport input parameters for the biosphere model, ANL-MGR-MD-000007 REV 01, 2003 b. Office of Civilian Radioactive Waste Management. USA

US DOe (US Department of Energy). 2004. Agricultural and environmental input parameters for the biosphere model. ANL-MGR-MD-000006 Rev02. Office of Civilian Radioactive Waste Management. USA 
US EPA (U.S. Environmental Protection Agency). 1994. Guidance manual for the Integrated Exposure Uptake Biokinetic model for lead in children. PB93-963510. Office of Solid Waste and Emergency Response. Washington, DC, USA

US EPA (U.S. Environmental Protection Agency). 1999a. Geochemistry and available Kd Values for Selected Inorganic Contaminants. Vol. 2, EPA-402-R-99-004b. Office of Air and Radiation, Washington, DC,USA

US EPA (U.S. Environmental Protection Agency). 1999b. Short sheet: IEUBK model soil/dust ingestion rates. EPA \#540-F-00-007. Office of Solid Waste and Emergency Response. Washington, DC, USA

US EPA (U.S. Environmental Protection Agency). 2005. Human Health Risk Assessment Protocol for hazardous waste combustion facilities (HHRAP). EPA/530/R-05-006. Office of Solid Waste. USA

US EPA (U.S. Environmental Protection Agency), Waste and cleanup risk assessment, Office of Solid Waste and Emergency Response, USA. Available at http://www.epa.gov/oswer/riskassessment/risk_superfund.htm

Volatier R. 2000. Enquête I individuelle et nationale sur les consommations alimentaires, Editions Technique \& Documentation, ISBN : 2-7430-0426-6. Editions Tec\&Doc, France. White PD, Van Leeuwen P, Davis BD, Maddaloni M, Hogan KA, Marcus AH, Elias RW. 1998. The conceptual structure of the integrated exposure uptake biokinetic model for lead in children. Environmental Health Perspectives 106 Suppl 6:1513-30

WHO (World Health Organization). 1993. Guidelines for drinking water quality. Vol. 1. Recommendations. Geneva, Switzeland

WHO (World Health Organization). 2000. Air quality guidelines for Europe, Second edition, WHO regional publications, European series, 91. Copenhagen, Danemark

Wilhelm M, Wittsiepe J, Schrey P, Hilbig A, Kersting M. 2005. Consumption of homegrown products does not increase dietary intake of arsenic, cadmium, lead, and mercury by young children living in an industrialized area of Germany. Science of Total Environment 343(13):61-70

Xintaras C. 1992. Analysis Paper : Impact of lead-contaminated soil on public health. ATSDR. Atlanta

Zupan M, Hudnik V, Lobnik F, Kadunc V. 1995. Accumulation of Pb, Cd and Zn from contaminated soil to various plants and evaluation of soil remediation with indicator plant 
(Plantago lanceolata L.). Contaminated soils: International conference on the biogeochemistry of trace elements, 15/05/95, Paris, France. Proceedings 85: 325-335 
Table 1: Cases investigated with the model B (because of uncertainty in the location of some children's houses, there are two entries for some children based on two different assumptions for soil concentrations and lead deposition around their houses)

\begin{tabular}{|c|c|c|c|c|c|c|}
\hline $\begin{array}{l}\text { child number } \\
\text { identification }\end{array}$ & $\begin{array}{c}\text { age } \\
\text { (month) }\end{array}$ & $\begin{array}{c}\text { blood lead } \\
(\mu \mathrm{g} / \mathrm{l})\end{array}$ & $\begin{array}{l}\text { distance to } \\
\text { the stacks } \\
\text { (m) }\end{array}$ & $\begin{array}{c}\text { \% home- } \\
\text { grown } \\
\text { fruit }\end{array}$ & $\begin{array}{l}\% \text { of home- } \\
\text { grown } \\
\text { vegetables }\end{array}$ & $\begin{array}{c}\text { surface soil lead } \\
\text { concentration in the } \\
\text { location of the child's } \\
\text { home }(\mathrm{mg} / \mathrm{kg})\end{array}$ \\
\hline 48 & 33 & 67.1 & 250 & 0 & 50 & 173 \\
\hline 28 & 47 & 83.1 & 900 & 75 & 75 & 96 \\
\hline 28 & 47 & 83.1 & 900 & 75 & 75 & 84 \\
\hline 27 & 74 & 41.5 & 900 & 62.5 & 75 & 96 \\
\hline 27 & 74 & 41.5 & 900 & 62.5 & 75 & 84 \\
\hline 41 & 52 & 31.9 & 450 & 10 & 20 & 112 \\
\hline 41 & 52 & 31.9 & 450 & 10 & 20 & 103 \\
\hline 71 & 65 & 44.7 & 150 & 0 & 0 & 203 \\
\hline 71 & 65 & 44.7 & 150 & 0 & 0 & 227 \\
\hline 90 & 37 & 44.7 & 300 & 0 & 0 & 261 \\
\hline 90 & 37 & 44.7 & 300 & 0 & 0 & 174 \\
\hline 97 & 81 & 22.3 & 1000 & 0 & 0 & 66 \\
\hline 43 & 21 & 108.7 & 450 & 0 & 0 & 112 \\
\hline 43 & 21 & 108.7 & 450 & 0 & 0 & 103 \\
\hline 50 & 71 & 99.1 & 200 & 0 & 0 & 493 \\
\hline
\end{tabular}


Table 2: Distributions assigned to environmental and chemical parameters of model B

\begin{tabular}{|c|c|c|}
\hline Parameters & Distributions & References \\
\hline $\begin{array}{l}\text { Fraction of wet deposition } \\
\text { that adheres to plant surfaces } \\
(-)\end{array}$ & $\mathrm{U}(0.15,1)^{\mathrm{a}}$ & GRNC 2002, US EPA 2005 \\
\hline $\begin{array}{l}\text { Deposition velocity of } \\
\text { particles }(\mathrm{m} / \mathrm{s})\end{array}$ & \begin{tabular}{ll}
\multicolumn{2}{c}{ CUM $^{\mathrm{b}}$} \\
perc. $^{\mathrm{c}}$ 0: $3 \mathrm{E}-4$ & perc. 84: 3 E-2 \\
perc. 16: 1 E-3 & perc. 100: 3 E-1 \\
perc. 50: 8 E-3 & \\
\end{tabular} & US DOe 2003b, c \\
\hline $\begin{array}{l}\text { Atmospheric mass loading } \\
\text { of particles }\left(\mathrm{kg} / \mathrm{m}^{3}\right)\end{array}$ & $\mathrm{T}(2.5 \mathrm{E}-8,1.2 \mathrm{E}-7,2.0 \mathrm{E}-7)$ & $\begin{array}{l}\text { ECETOC 1992, US DOe } \\
\text { 2003b, c }\end{array}$ \\
\hline \multicolumn{3}{|c|}{ Yield of crops $\left(\mathrm{kg} / \mathrm{m}^{2}\right)$} \\
\hline Leafy vegetables & $\mathrm{U}(0.1,0.5)$ & GRNC 2002, US DOe 2004 \\
\hline Fruiting vegetables & $\mathrm{U}(0.1,0.3)$ & US DOe 2004 \\
\hline Fruits & $\mathrm{U}(0.2,0.5)$ & GCNC 2002, US DOe 2004 \\
\hline \multicolumn{3}{|c|}{ Plant surface loss coefficient $\left(\right.$ year $\left.^{-1}\right)$} \\
\hline Leafy vegetables & $\mathrm{T}(11,26,51)^{\mathrm{d}}$ & GRNC 2002 \\
\hline $\begin{array}{l}\text { Fruiting vegetables and } \\
\text { fruits }\end{array}$ & $\mathrm{T}(8.4,18,51)$ & US DOe 2004 \\
\hline \multicolumn{3}{|c|}{ Length of plant exposure to deposition (year) } \\
\hline Leafy vegetables & $\mathrm{T}(0.12,0.21,0.58)$ & \multirow{2}{*}{$\begin{array}{c}\text { GCNC 2002, GRNC 2002, } \\
\text { US EPA } 2005\end{array}$} \\
\hline $\begin{array}{l}\text { Fruiting vegetables and } \\
\text { fruits }\end{array}$ & $\mathrm{T}(0.16,0.25,0.41)$ & \\
\hline \multicolumn{3}{|c|}{ Interception fraction of the edible portion of crops (-) } \\
\hline Leafy vegetables & $\mathrm{T}(0.10,0.20,0.50)$ & $\begin{array}{c}\text { Baes 1984, GCNC 2002, } \\
\text { GRNC 2002. US EPA 2005 }\end{array}$ \\
\hline Fruiting vegetables & $\mathrm{T}(0.03,0.15,0.15)$ & \multirow[t]{2}{*}{ Baes 1984, US EPA 2005} \\
\hline Fruits & $\mathrm{T}(0.03,0.10,0.10)$ & \\
\hline \multicolumn{3}{|c|}{ Dry matter of plants $(\%)$} \\
\hline Leafy vegetables & $\mathrm{T}(0.05,0.07,0.12)$ & \multirow{4}{*}{$\begin{array}{c}\text { Baes 1984. US DOe } 2004 . \\
\text { APRIFEL } 2008\end{array}$} \\
\hline Fruiting vegetables & $\mathrm{T}(0.04,0.07,0.10)$ & \\
\hline Fruits & $\mathrm{T}(0.10,0.15,0.18)$ & \\
\hline Root-vegetables & $\mathrm{T}(0.12,0.20,0.22)$ & \\
\hline \multicolumn{3}{|c|}{ Soil to plant transfer coefficients (kg dry matter / kg dry matter) } \\
\hline Leafy vegetables & $\mathrm{LN}(3.0 \mathrm{E}-2,4.6 \mathrm{E}-2,9.6 \mathrm{E}-4,2.8 \mathrm{E}-1)^{\mathrm{e}}$ & \multirow{3}{*}{$\begin{array}{l}\text { Tremel-Schaub and Feix } \\
\text { 2005, Zupan et al. } 1995\end{array}$} \\
\hline $\begin{array}{l}\text { Fruiting vegetables and } \\
\text { fruits }\end{array}$ & $\mathrm{LN}(4.2 \mathrm{E}-3,3.1 \mathrm{E}-3,6.1 \mathrm{E}-4,1.9 \mathrm{E}-2)$ & \\
\hline Root-vegetables & LN (5.7 E-3, 7.3 E-3 , 2.7 E-4, 4.5 E-2) & \\
\hline
\end{tabular}

${ }^{a} \mathrm{U}(\mathrm{x} 1, \mathrm{x} 2)$ specifies a uniform distribution with minimum $\mathrm{x} 1$ and maximum $\mathrm{x} 2$.

${ }^{\mathrm{b}}$ CUM stands for cumulative distribution.

${ }^{c}$ perc. stands for percentile.

${ }^{\mathrm{d}} \mathrm{T}(\mathrm{x} 1, \mathrm{x} 2, \mathrm{x} 3)$ specifies a triangular distribution with minimum $\mathrm{x} 1$, mode $\mathrm{x} 2$ and maximum $\mathrm{x} 3$.

${ }^{\mathrm{e}} \mathrm{LN}(\mathrm{x} 1, \mathrm{x} 2, \mathrm{x} 3, \mathrm{x} 4)$ specifies a lognormal distribution with mean $\mathrm{x} 1$, standard deviation $\mathrm{x} 2$, lower truncation limit $\mathrm{x} 3$ and upper truncation limit $\mathrm{x} 4$. 
Table 3: Input parameters with the highest sensitivity on exposure produce concentrations in model A

\begin{tabular}{|l|c|c|}
\hline Parameters & Symbols & Rank correlation coefficients between the \\
& & input parameter and exposure produce \\
coefficient & Kd & -0.44 \\
\hline Particle-water partition & & 0.41 \\
\hline Leaf wet density & Cs & 0.37 \\
\hline Primary production dry & veg_prod & 0.31 \\
\hline vegetation & & \\
\hline Rainsplash & Temp & 0.21 \\
\hline Leaf surface erosion half-life & Thalf_le & 0.14 \\
\hline Stem wet density & rho_stem & -0.12 \\
\hline Annual average precipitation & rainsplash & 0.09 \\
\hline Ambient environmental & & \\
\hline Land surface runoff & & \\
\hline
\end{tabular}


Figure 1 : Distributions of the measured concentrations and of the concentrations calculated with model A in air (a), ground soil (b), exposed produce (c), protected produce (d) and blood lead (e) (for blood lead, concentrations were also predicted by IEUBK from measurements in the other media)
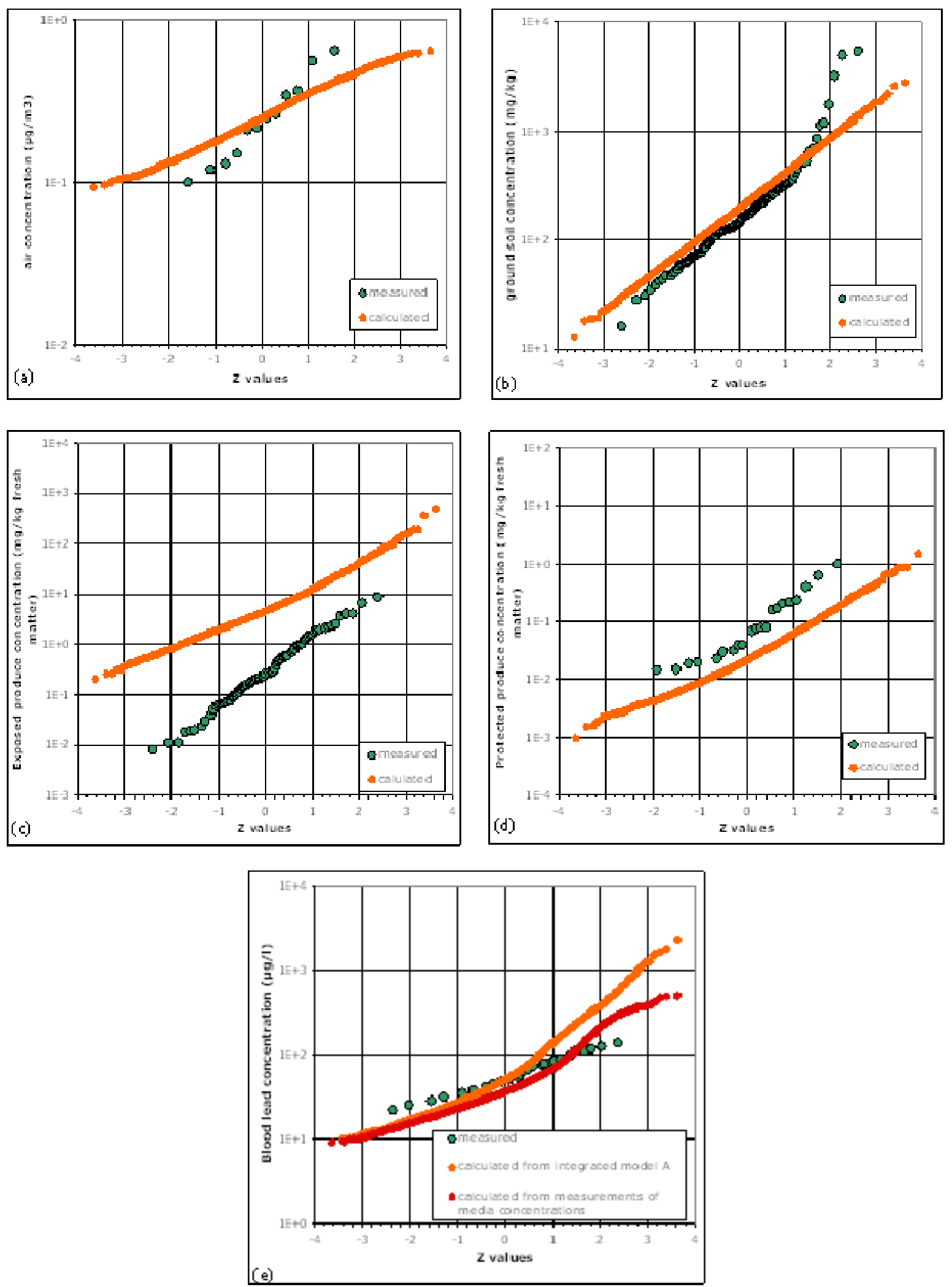
Figure 2: Contributions of the exposure routes to the lead uptake according to model A

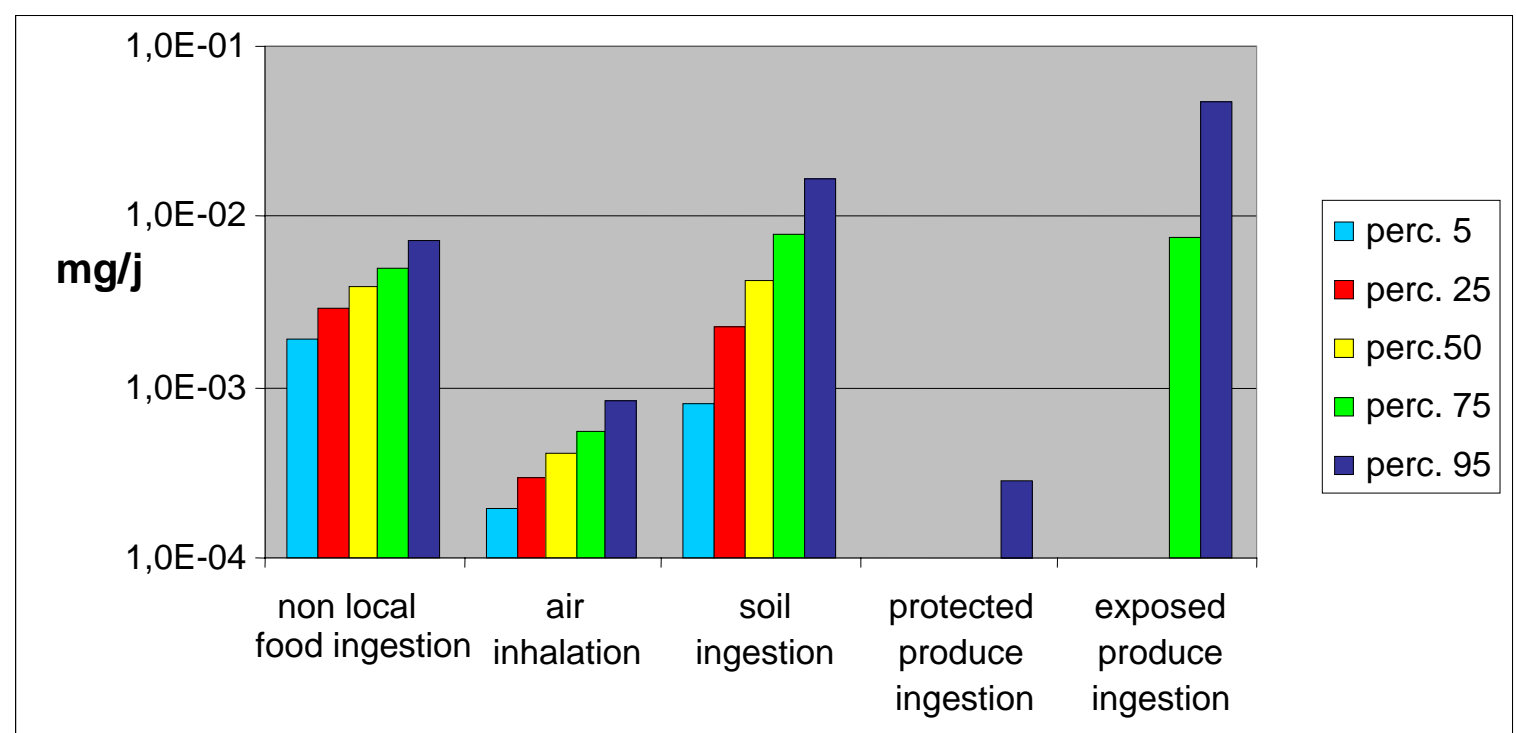


Figure 3: Distributions of the measured concentrations and of the concentrations calculated in exposed produce (a) and blood lead (b) before and after correcting the value of leaf wet density in model A
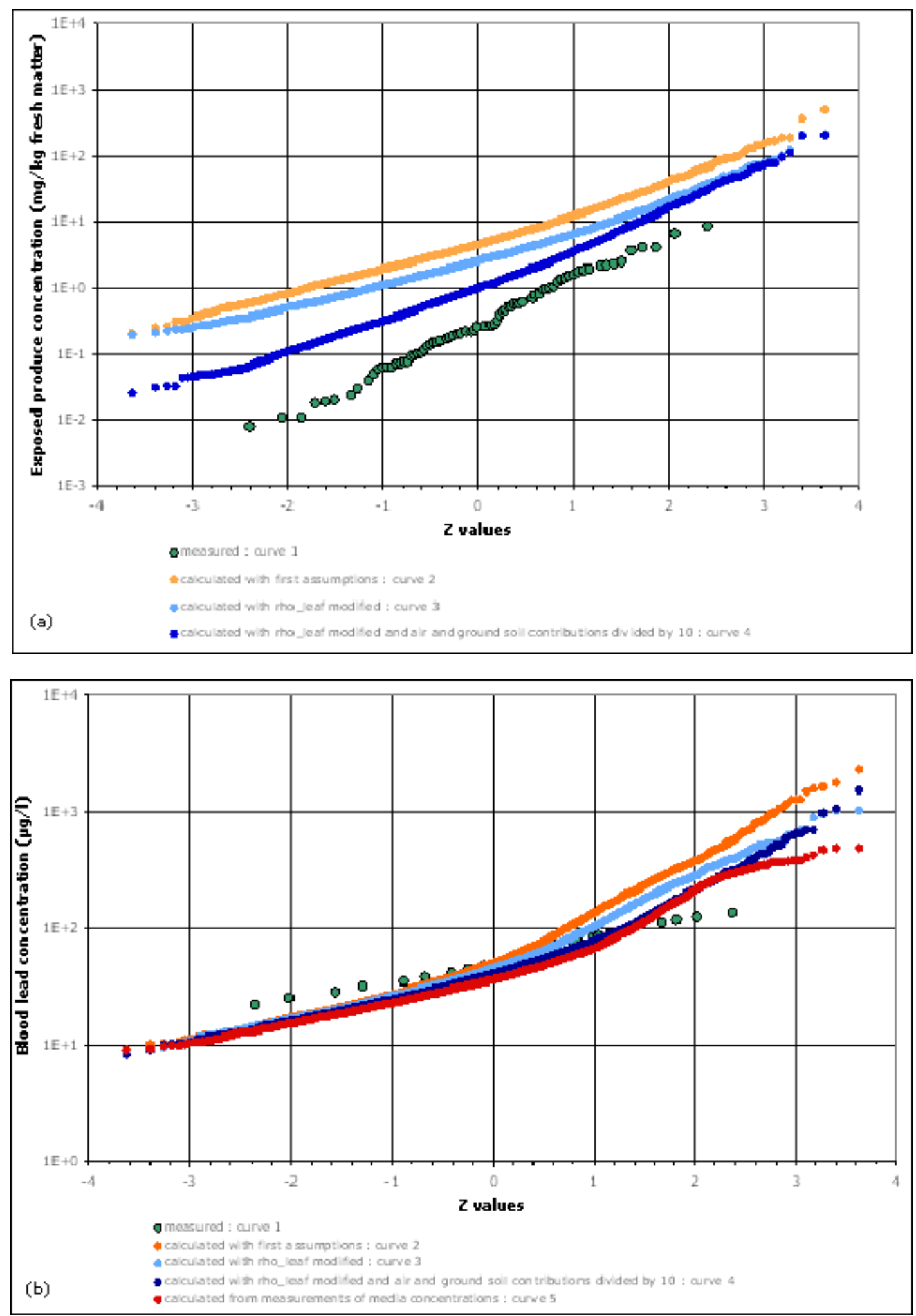
Figure 4: Comparison of the calculated and observed blood lead concentrations for the subsample of tested children (because of uncertainty in the location of some children's houses, there are two entries for some children based on two different assumptions for soil concentrations and atmospheric deposition around their houses) - the error bars show the range (from the $5^{\text {th }}$ to the $95^{\text {th }}$ percentile) of calculated concentrations with model B

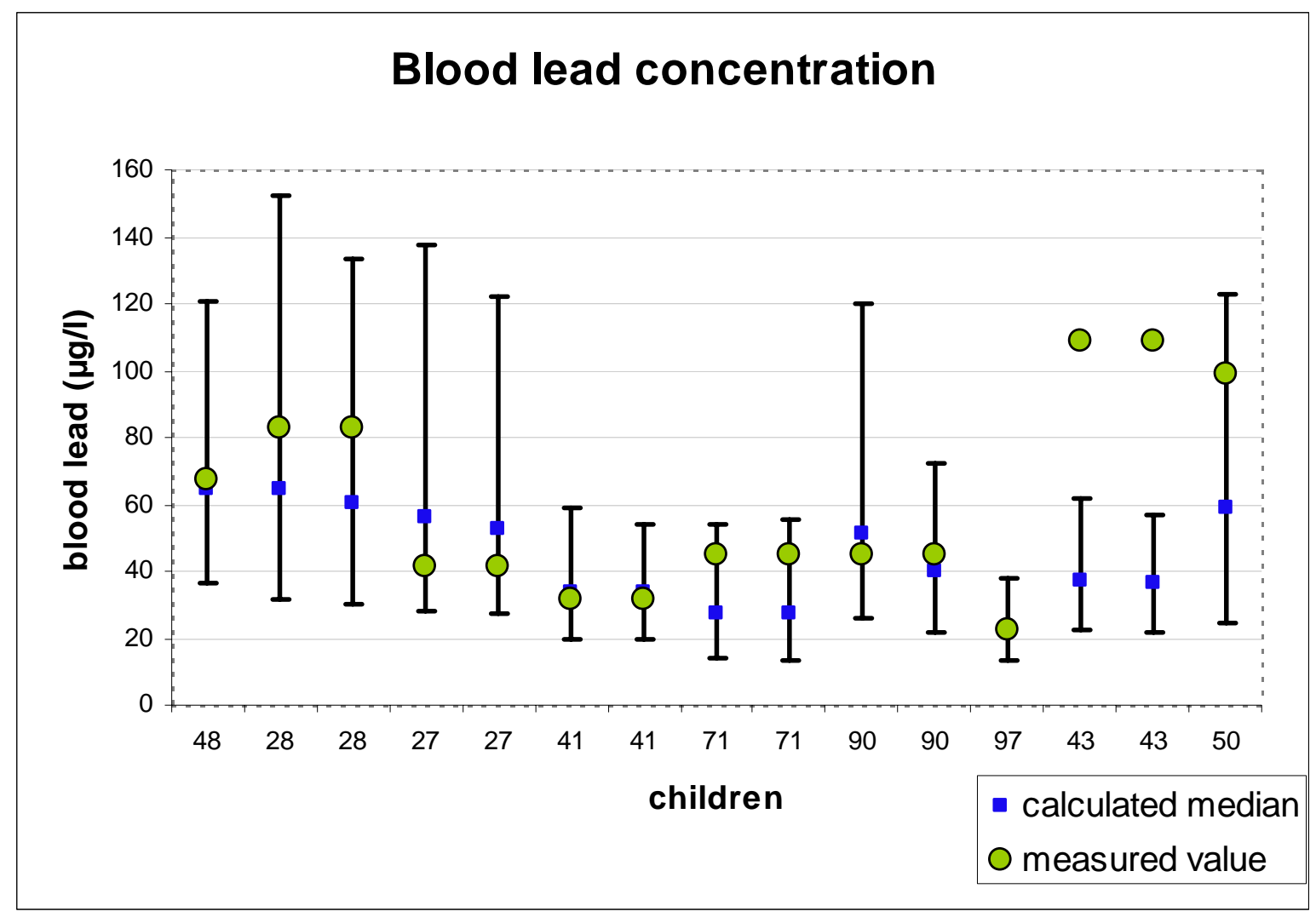

